\title{
Two months of radiation oncology in the heart of Italian "red zone" during COVID-19 pandemic: paving a safe path over thin ice
}

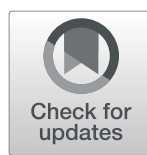

Michela Buglione ${ }^{1}$, Luigi Spiazzi ${ }^{2}$, Andrea Emanuele Guerini ${ }^{1}$, Fernando Barbera², Nadia Pasinetti ${ }^{{ }^{*}}$ (D), Ludovica Pegurri ${ }^{2}$, Luca Triggiani ${ }^{1}$, Davide Tomasini ${ }^{1}$, Diana Greco ${ }^{2}$, Gianluca Costantino ${ }^{1}$, Alessandra Bragaglio ${ }^{2}$, Nadia Bonometti ${ }^{2}$, Mara Liccioli ${ }^{2}$, Lorella Mascaro ${ }^{2}$, Radiation Oncology Department Staff, Filippo Alongi ${ }^{1}$ and Stefano Maria Magrini ${ }^{1}$

\begin{abstract}
Background: Coronavirus Disease 2019 (COVID-19) pandemic had an overwhelming impact on healthcare worldwide. Outstandingly, the aftermath on neoplastic patients is still largely unknown, and only isolated cases of COVID-19 during radiotherapy have been published. We will report the two-months experience of our Department, set in Lombardy "red-zone".

Methods: Data of 402 cancer patients undergoing active treatment from February 24 to April 24, 2020 were retrospectively reviewed; several indicators of the Department functioning were also analyzed.

Results: Dedicated measures allowed an overall limited reduction of the workload. Decrease of radiotherapy treatment number reached $17 \%$, while the number of administration of systemic treatment and follow up evaluations kept constant. Conversely, new treatment planning faced substantial decline. Considering the patients, infection rate was 3.23\% (13/402) and mortality 1.24\% (5/402). Median age of COVID-19 patients was 69.7 years, the large majority were male and smokers (84.6\%); lung cancer was the most common tumor type (61.5\%), $84.6 \%$ of subjects were stage III-IV and $92.3 \%$ had comorbidities. Remarkably, $92.3 \%$ of the cases were detected before March 24. Globally, only $2.5 \%$ of ongoing treatments were suspended due to suspect or confirmed COVID-19 and $46.2 \%$ of positive patients carried on radiotherapy without interruption. Considering only the last month, infection rate among patients undergoing treatment precipitated to $0.43 \%(1 / 232)$ and no new contagions were reported within our staff.
\end{abstract}

Conclusions: Although mortality rate in COVID-19 cancer patients is elevated, our results support the feasibility and safety of continuing anticancer treatment during SARS-Cov-2 pandemic by endorsing consistent preventive measures.

Keywords: COVID-19, Radiotherapy, Radiation oncology, Cancer, Coronavirus, Anticancer

\footnotetext{
* Correspondence: nadia.pasinetti@aol.com

'Department of Radiation Oncology, Brescia University, Università degli Studi

di Brescia, Piazzale Spedali Civili 1, 25123 Brescia, Italy

Full list of author information is available at the end of the article
}

\section{$\triangle B M C$}

(c) The Author(s). 2020 Open Access This article is licensed under a Creative Commons Attribution 4.0 International License, which permits use, sharing, adaptation, distribution and reproduction in any medium or format, as long as you give appropriate credit to the original author(s) and the source, provide a link to the Creative Commons licence, and indicate if changes were made. The images or other third party material in this article are included in the article's Creative Commons licence, unless indicated otherwise in a credit line to the material. If material is not included in the article's Creative Commons licence and your intended use is not permitted by statutory regulation or exceeds the permitted use, you will need to obtain permission directly from the copyright holder. To view a copy of this licence, visit http://creativecommons.org/licenses/by/4.0/ The Creative Commons Public Domain Dedication waiver (http://creativecommons.org/publicdomain/zero/1.0/) applies to the data made available in this article, unless otherwise stated in a credit line to the data. 


\section{Background}

Italy has been the first western-world country massively hit by Coronavirus disease 19 (COVID-19). Since the first reported local transmission on 21st February 2020, the outbreak mainly involved northern area, with Lombardy standing out as the second region with most deaths worldwide after New York state, but with half of the population (http://www.salute.gov.it/imgs/C_17_notizie_4640_0_file. pdf) [1]. Our Radiation Oncology Department is set in the main hospital of the city of Brescia, known for being the province with the second higher number of confirmed cases in Italy (http://www.salute.gov.it/imgs/C_17_notizie_4640_1_file.pdf). Measures to hinder the dissemination of the virus were considerably curbed by the complexity of its detection, as the clinical presentation of Covid-19 is heterogeneous and a large proportion of the patient is asymptomatic. The scenario is even more intricate in cancer patients, as manifestations of the tumor and side effects of the treatment might mimic COVID-19 [2, $3]$. Although this pandemic massively spread worldwide, the impact on neoplastic patients is still largely unknown. Currently, only a few retrospective reports have been published, including a small number of subjects on active treatment and suggesting that cancer patients might be prone to develop severe presentations of COVID-19 [4]. In this period of uncertainty, these very preliminary data could induce physicians to abstain from life-saving treatments in fear of the risk of infection. As one of the main Radiation Oncology Departments of Lombardy, we will attempt to delineate a comprehensive picture of our experience.

\section{Methods}

Data of all the cancer patients who underwent anti-cancer treatments, including radiation therapy, chemotherapy and other systemic therapies at Brescia University Radiation Oncology Department from February 24 to April 24, 2020 were retrospectively analyzed. We also identified patients with a confirmed diagnosis of COVID-19, defined according to the WHO criteria, with a positive real-time polymerase chain-reaction (RT-PCR) assay for SARSCoV-2 on a naso-pharyngeal swab. Demographic, clinical and treatment characteristics were retrieved from the medical records and from our Institution's archiving systems. Data regarding the workload of our four accelerators, the number of new treatment planning procedures and of the accesses to our Day Hospital for systemic treatment and the number of absences of our staff have been retrieved from our institutional registry.

\section{Results}

COVID-19 impact on the organization of the department Our Department is equipped with a treatment area with four linacs (two Elekta Synergy ${ }^{\oplus}$, a tomotherapy equipment -Accuray Radixact ${ }^{\oplus}$ - and a Cyberknife $^{\circledast}$ ). Of note, Cyberknife ${ }^{\bullet}$ was recently installed and therefore its workload was already limited due to the ongoing process of implementation. Other facilities include an inpatient ward with 22 beds, a Day-Hospital with dedicated rooms for visits and administration of systemic therapies and a brachitherapy unit. Coping with COVID-19 required a profound reorganization with the aim to continue treatment administration. All the personnel was required to wear appropriate personal protective equipment (PPE): surgical masks and gloves through the whole shift and further protections (including FFP-2/3 respirators, waterproof gowns and cuff, face-shield or goggles and shoecover) in case of direct contact with suspect or RT-PCR positive patients. Staff members that reported direct contacts with positive or suspect cases or manifested fever or respiratory symptoms were monitored with repeated RT-PCR tests for SARS-Cov-2 on nasopharyngeal swab.

Patients on active treatment underwent SARS-Cov-2 screening according to the same criteria; they were also guided with detailed instructions regarding social and hygienic rules and required to wear surgical masks and sanitize their hands when accessing the Department. Since the beginning of March, all the people accessing the hospital were screened for body temperature. In addition, we established a day time phone counseling service for cancer patients seeking medical advice; the attending physician was also responsible of the internal triage procedure, run in a dedicated room to evaluate the subjects with suggestive symptoms.

The treatment priority for each indication was evaluated on the characteristics of the patient and the disease, following general principles $[5,6]$ that were tailored on a case by case basis. Priority was given to treatments with curative intent and which effectiveness could be significantly affected by delay. All the procedures that could be deferred without an outcome impairment were postponed. Prescription of palliative radiotherapy was shifted when possible towards modulation of analgesic or systemic treatment. Scheduled follow-up visits were replaced by telephone interviews whenever possible: reports of imaging and laboratory tests were transmitted by e-mail or fax or retrieved from our hospital's archiving system, examined and compared to previous evaluations by a physician that afterwards contacted the patient to ascertain his conditions and list a new appointment.

Radiation treatment of positive or symptomatic patients, accordingly to their clinical conditions, was performed on a dedicated linear accelerator (Synergy ${ }^{\bullet} 2$ ), at the end of the shift to avoid contacts with other people, using the appropriate PPE and carefully sanitizing the room after each treatment. 
Our ward went through a progressive transformation: at first some rooms with assigned nurses and facilities were arranged for isolation, as no rooms in COVID-19 dedicated wards were available during the epidemic peak. In fact, despite five wards of our Hospital were reallocated with this purpose, they were completely occupied due to the inflow of hundreds of patients. Subsequently, the increasing number of positive patients determined a complete conversion of our ward into a "COVID-ward". At peak, seven positive subjects occupied our rooms, while other patients necessitating hospitalization were transferred to other "clean" wards. Additional preventive measures were implemented: swabs were performed periodically to all our staff and to every patient requiring hospitalization before admission; visits from patients' relatives were forbidden. Since April 17 our ward returned "COVID-free", a condition maintained up to date (June 06).

\section{COVID-19 impact on the workload of the department}

The enforcement of the above mentioned procedures resulted in a relatively limited reduction the overall workload of our four linear accelerators. The number of radiotherapy sessions provided each day is represented in Table 1 and Fig. 1a: the maximum decrease of total treatment number reached $17 \%$ and later contracted to $11 \%$. The accelerator dedicated to the treatment of COVID-19 positive or suspect patients suffered a somewhat greater decrease (about 20\%) due to time consuming sanitizing procedures that approximately doubled the duration of each session. Conversely, planning of new treatments faced a remarkable reduction (about $50 \%)$ throughout the whole month of March due to postponement of deferrable treatments and the need to avoid overcrowding of the waiting rooms. The relative reduction of brachytherapy treatments was mainly due to the deferral of treatment of low risk prostate cancer, while integrated treatments were granted. The administration of systemic treatment did not suffer a significant decrease, with a stable number of about 40-50 weekly accesses and periodic slight deflections unrelated to COVID-19, mainly due to logistical reasons and different treatments' duration (Table 1, Fig. 1b). Scheduled follow-up visits were postponed or processed through telemedicine as stated above. An almost complete switch towards this modality allowed to maintain an overall stable number of follow up evaluations, as highlighted in Table 1.

Several of our patients considered discontinuation of ongoing life-saving treatments, frightened that hospital accesses could expose them to contagion: ten patients actually refused to start their treatment on the planned date, while no ongoing treatment was stopped for patient's decision.

\section{COVID-19 impact on the staff}

Characteristics of the impact of COVID-19 on our personnel are summarized in Table 2 and Fig. 1c. Our staff during the index period included a total of 87 professionals: 15 radiation oncologists, (of whom 5 temporarily employed), 17 radiation oncology trainees, 27 nurses, 22 radiation therapists and 6 physicists (4 full

Table 1 a) number of daily provided radiation treatments by week for each linear accelerator (Syn $=$ Synergy ${ }^{\oplus}$, Rdx $=$ Radixact $^{\oplus}$, Cyber = Cyberknife ${ }^{\oplus}$, COVID+ = COVID-19 positive patients), total number of daily administered radiation treatments by week (Total) and weekly number of new treatments planning (Planning); number of weekly brachytherapy treatments (Brachy); number of weekly provided systemic treatment at our Day-Hospital (DH systemic t.), new patients first evaluation (admissions), in person follow up (FU i.p.), telemedicine follow up (Telemedicine FU) and total follow up evaluations (Total FU)

\begin{tabular}{|c|c|c|c|c|c|c|c|c|c|c|c|c|c|}
\hline Week & $\begin{array}{l}\text { Syn } \\
1\end{array}$ & $\begin{array}{l}\text { Syn } \\
2\end{array}$ & $\begin{array}{l}\text { Syn } 2 \\
\text { covid+ }\end{array}$ & $R d x$ & Cyber & Total & Planning & Brachy & $\begin{array}{l}\text { DH systemic } \\
\text { t. }\end{array}$ & Admissions & $\begin{array}{l}\text { FU i. } \\
\text { p. }\end{array}$ & $\begin{array}{l}\text { Telemedicine } \\
\text { FU }\end{array}$ & $\begin{array}{l}\text { Total } \\
\text { FU. }\end{array}$ \\
\hline 3-7 Feb & 51 & 45 & 0 & 36 & 0 & 132 & 94 & 11 & 41 & 32 & 107 & 0 & 107 \\
\hline 10-14 Feb & 44 & 44 & 0 & 37 & 4 & 129 & 84 & 9 & 48 & 30 & 100 & 0 & 100 \\
\hline 17-21 Feb & 49 & 42 & 0 & 34 & 5 & 130 & 118 & 7 & 29 & 34 & 92 & 0 & 92 \\
\hline 24-28 Feb & 48 & 42 & 0 & 33 & 4 & 127 & 112 & 5 & 43 & 32 & 46 & 42 & 88 \\
\hline 2-6 Mar & 50 & 44 & 0 & 37 & 7 & 138 & 90 & 7 & 49 & 34 & 34 & 53 & 87 \\
\hline 9-13 Mar & 48 & 43 & 0 & 30 & 6 & 127 & 66 & 3 & 41 & 21 & 18 & 75 & 93 \\
\hline 16-20 Mar & 51 & 36 & 2 & 34 & 7 & 128 & 60 & 9 & 42 & 23 & 4 & 79 & 83 \\
\hline 23-27Mar & 50 & 36 & 4 & 32 & 4 & 122 & 52 & 5 & 47 & 25 & 7 & 93 & 100 \\
\hline $\begin{array}{l}30 \text { Mar - } 3 \\
\text { Apr }\end{array}$ & 44 & 38 & 6 & 30 & 2 & 114 & 54 & 7 & 49 & 30 & 7 & 85 & 92 \\
\hline 6-10 Apr & 46 & 33 & 4 & 29 & 1 & 109 & 82 & 10 & 43 & 25 & 10 & 88 & 98 \\
\hline 13-17 Apr & 43 & 36 & 6 & 29 & 2 & 110 & 60 & 8 & 37 & 25 & 11 & 78 & 89 \\
\hline 20-24 Apr & 48 & 35 & 2 & 31 & 3 & 117 & 66 & 14 & 45 & 27 & 15 & 87 & 102 \\
\hline
\end{tabular}




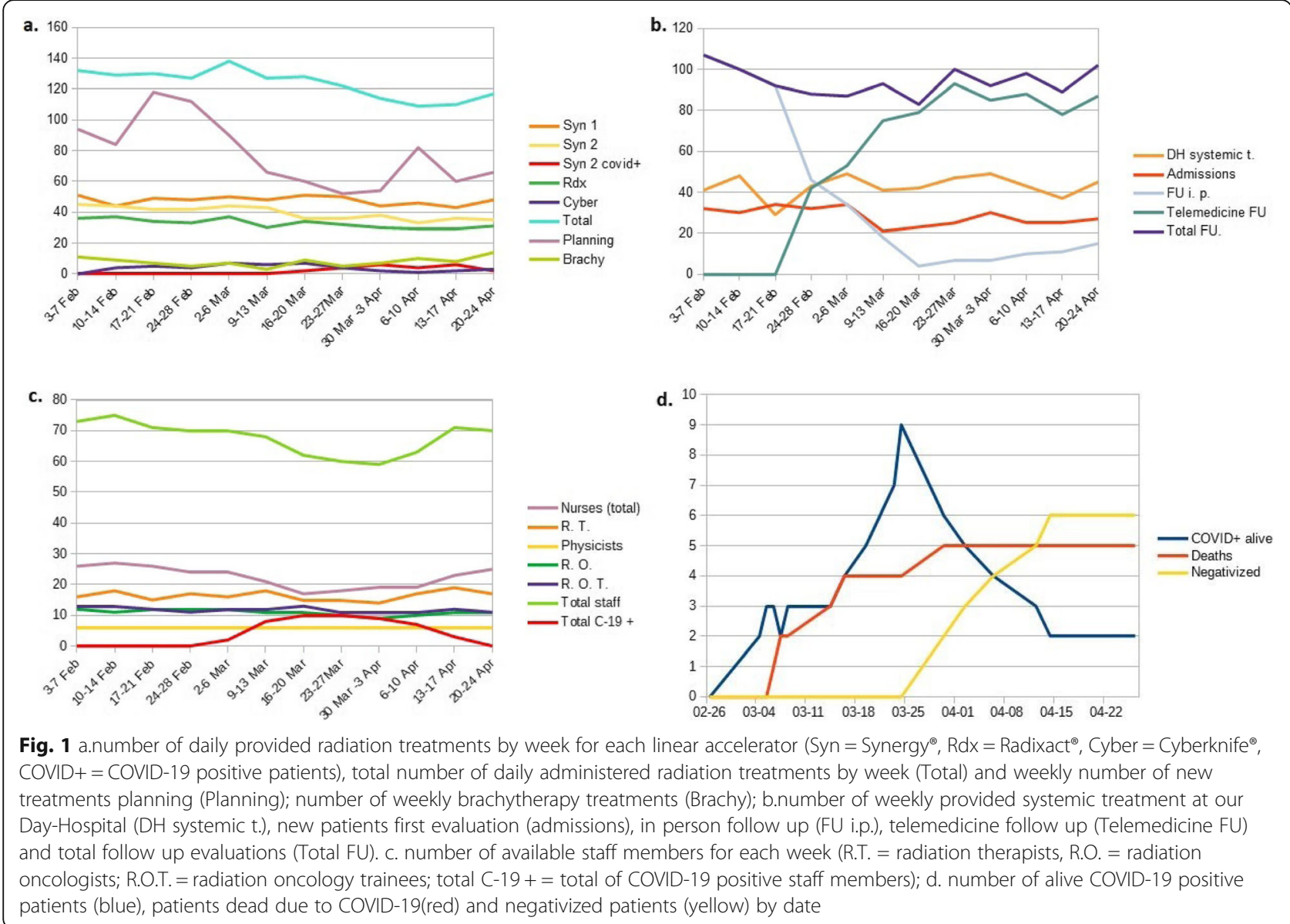

time and 2 part-time assigned to our Department). Nine symptomatic subjects received a positive nasopharyngeal swab assay for SARS-Cov-2, three tested positive while asymptomatic and seven displayed a distinctive clinical presentation with negative RT-PCR. It has to be noted that all the positive cases among our staff were reported between 2nd and 17th of March. Infection rate was $13.7 \%$ among the total staff, with comparable numbers for radiation oncologists, trainees, dayhospital nurses and radiation therapists. No cases were identified within physicists, while $33.3 \%$ of ward nurses tested positive. Symptoms were mild and managed with household isolation in almost all cases, with only our ward head-nurse requiring hospitalization for severe pneumonia. A relative shortage of personnel was evident from the second week of March to the first third of April. This required a temporary reallocation to our inpatient ward of three nurses from our day-hospital and of two nurses from the Oncology Department.

\section{COVID-19 impact on the patients}

Of the 23 patients on active treatment with a suggestive clinical presentation, 13 tested positive and 10 negative for RT-PCR assay. Considering the index period
(February 24 to April 24), 402 patients underwent active treatment at our Center, of whom 324 were administered radiotherapy or radio-chemotherapy and 78 only systemic treatments. Therefore, the infection rate among patients receiving active treatment was $3.23 \%$ and the mortality rate was $1.24 \%$ (5 deaths). Characteristics of the positive patients are outlined in Table 3 and Table 4. Median age was 69.7 years and the large majority of patients were male (84.6\%), active or former smokers (84.6\%) with an Eastern Cooperative Oncology Group Performance Status (ECOG-PS) of $0-1$ (84.6\%). The most common cancer type was Non-Small Cell Lung Cancer (NSCLC), totaling $61.5 \%$ of cases, followed by Head and Neck Squamous Cell Carcinoma (15.4\%); $84.6 \%$ were stage III-IV. Almost all the subjects bore comorbidities, with $38.5 \%$ presenting three or more, mostly represented by cardiovascular diseases. Timeline of confirmed infections is illustrated in Fig. 1d. Remarkably, 12 of the 13 first positive tests were collected before March 24 and 4 of the 5 deaths occurred within March 16. While two of the deceased were on palliative treatment and already in bad general conditions (ECOG-PS 3), the other three were in initially fair conditions and receiving radical treatments for locally advanced disease. Of the 
Table 2 Number of available staff members for each week ( $\mathrm{W}=$ ward; DH = day-hospital, R.T. = radiation therapists, hw = home working, R.O. = radiation oncologists; R.O.T. = radiation oncology trainees, total C-19+= total of COVID-19 positive staff members) and percentage of absences of total staff. In the last lines, total number of units for each category and infection rates are reported

\begin{tabular}{|c|c|c|c|c|c|c|c|c|c|c|}
\hline & $\begin{array}{l}\text { Nurses } \\
\text { (W) }\end{array}$ & $\begin{array}{l}\text { Nurses } \\
(\mathrm{DH})\end{array}$ & $\begin{array}{l}\text { Nurses } \\
\text { (total) }\end{array}$ & R. T. & $\begin{array}{l}\text { Physicists } \\
\text { (hw) }\end{array}$ & R. O. & R. O. T. & $\begin{array}{l}\text { Total } \\
\text { staff }\end{array}$ & $\begin{array}{l}\text { Total C-19 } \\
+\end{array}$ & $\begin{array}{l}\% \\
\text { absences }\end{array}$ \\
\hline 3-7 Feb & 15 & 11 & 26 & 16 & $6(1)$ & 12 & 13 & 73 & $0(0 \%)$ & $16.1 \%$ \\
\hline 10-14 Feb & 15 & 12 & 27 & 18 & $6(1)$ & 11 & 13 & 75 & $0(0 \%)$ & $13.8 \%$ \\
\hline 17-21 Feb & 15 & 11 & 26 & 15 & $6(1)$ & 12 & 12 & 71 & $0(0 \%)$ & $18.4 \%$ \\
\hline 24-28 Feb & 14 & 10 & 24 & 17 & $6(1)$ & 12 & 11 & 70 & $0(0 \%)$ & $19.5 \%$ \\
\hline 2-6 Mar & 14 & 10 & 24 & 16 & $6(1)$ & 12 & 12 & 70 & $2(2.3 \%)$ & $19.5 \%$ \\
\hline 9-13 Mar & 14 & 7 & 21 & 18 & $6(1)$ & 11 & 12 & 68 & $8(9.2 \%)$ & $21.8 \%$ \\
\hline 16-20 Mar & 9 & 8 & 17 & 15 & $6(1)$ & 11 & 13 & 62 & 10 (11.5\%) & $28.7 \%$ \\
\hline 23-27Mar & 10 & 8 & 18 & 15 & $6(1)$ & 10 & 11 & 60 & 10 (11.5\%) & $31.0 \%$ \\
\hline $30 \mathrm{Mar}-3 \mathrm{Apr}$ & 9 & 10 & 19 & 14 & $6(1)$ & 9 & 11 & 59 & $9(10.3 \%)$ & $32.2 \%$ \\
\hline 6-10 Apr & 9 & 10 & 19 & 17 & $6(1)$ & 10 & 11 & 63 & $7(8 \%)$ & $27.6 \%$ \\
\hline 13-17 Apr & 13 & 10 & 23 & 19 & $6(1)$ & 11 & 12 & 71 & $3(3.4 \%)$ & $18.4 \%$ \\
\hline 20-24 Apr & 14 & 11 & 25 & 17 & $6(1)$ & 11 & 11 & 70 & 0 & $19.5 \%$ \\
\hline Total & 15 & 12 & 27 & 22 & 6 & 15 & 17 & 87 & & \\
\hline COVID-19 + symptomatic & $5(33.3 \%)$ & $1(8.3 \%)$ & $6(22.2 \%)$ & $\begin{array}{l}2 \\
(9.1 \%)\end{array}$ & $0(0 \%)$ & $0(0 \%)$ & $1(5.8 \%)$ & $9(10.3 \%)$ & & \\
\hline $\begin{array}{l}\text { COVID-19+ } \\
\text { Asymptomatic }\end{array}$ & $0(0 \%)$ & $0(0 \%)$ & $0(0 \%)$ & $\begin{array}{l}1 \\
(4.5 \%)\end{array}$ & $0(0 \%)$ & $\begin{array}{l}2 \\
(13.3 \%)\end{array}$ & $0(0 \%)$ & $3(3.4 \%)$ & & \\
\hline COVID-19 - symtomatic & $1(6.7 \%)$ & $4(33.3 \%)$ & $5(18.5 \%)$ & $0(0 \%)$ & $0(0 \%)$ & $0(0 \%)$ & $\begin{array}{l}2 \\
(11.8 \%)\end{array}$ & $7(8 \%)$ & & \\
\hline
\end{tabular}

other positive patients, six carried on radiotherapy (in two cases with hypofractionation of the remaining dose) without a break; a single treatment was definitively halted before the planned dose and one underwent a prolonged stop (due to admission to another hospital) and restarted RT 45 days later after dose replanning. Of the 10 patients with suggestive symptoms and a swab negative for SARS-Cov-2, two continued radiotherapy without interruption, three restarted it after a short delay (median of 4 days) and two were admitted to other hospitals with consequent prolonged discontinuation (over 30 days) that will require a new treatment planning; two adjuvant chemotherapy cycles have also been postponed. Suggestive imaging findings were identified on chest Xray of COVID- 19 positive patients in $84.6 \%$ of the cases and in all the chest CT-scans performed. All the positive cases were periodically evaluated also by the colleagues of infectious disease and anesthesiology departments and the majority was treated off-label with hydroxychloroquine $(84.6 \%)$, antiviral drugs $(84.6 \%)$ and azythromicin (69.2\%); three patients also received tocilizumab (23.1\%). Six patients (46.2\%) developed severe disease, defined as necessity of high-flow supplemental oxygen. Supplemental oxygen was administered to $84.6 \%$ of patients and Continuous-Positive-Airway-Pressure to one patient. None of our patients was offered invasive ventilation, due to the absence of indication attributable to prognosis and general conditions in two cases and in three cases also due to the overwhelmingly high number of patients treated at our hospital Intensive Care Unit during the outbreak peak, with consequent lack of available facilities. Six patients were discharged after full clinical recovery and negative RT-PCR on a naso-pharyngeal swab and two were transferred to other institutions at symptoms resolution, although still positive.

\section{Discussion}

Coronavirus-disease-2019 outbreak is currently generating an overwhelming burden for public health worldwide: up to date, $6,663,304$ confirmed cases and 392, 802 deaths were disclosed. (https://www.who.int/docs/ default-source/coronaviruse/situation-reports/2020042 9-sitrep- 100-covid-19.pdf?sfvrsn=bbfbf3d1_6). Oncology and radiation oncology practice have been affected as well, as the urgency of providing life-saving treatments could be undermined by the risk of infection. This generated a large body of recommendations, surveys and guidelines [5-8]. Nevertheless, currently published clinical data are still limited, especially considering subjects on active treatment [9-16].

Previous series, including from 3 to 69 COVID-19 positive patients, reported an infection rate ranging from 0.79 to $2.7 \%$ among cancer patients and a mortality rate of $0-36 \%$ in infected subjects [10-20]. Only a fraction of 
Table 3 Main COVID-19 positive patients' characteristics

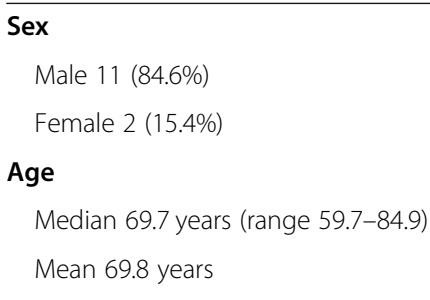

\section{ECOG Performance Status}

PSO 3 (23.1\%)

PS1 8 (61.5\%)

PS2 $0(0 \%)$

PS3 2 (15.4\%)

\section{Smoking habit}

Smoker 9 (69.2\%)

Former smoker (15.4\%)

Non smoker (15.4\%)

\section{Comorbidities}

Arterial hypertension 4 (30.7\%)

Other cardiovascular diseases 6 (46.2\%)

Arrhytmias 2 (15.4\%)

Diabetes 2 (15.4\%)

Infectious diseases 2 (15.4\%)

Gastrointestinal diseases 2 (15.4\%)

\section{Number of comorbidities}

None 1 (7.7\%)

One 4 (30.8\%)

Two $323.1 \%$

Three or more 5 (38.5\%)

\section{Tumor diagnosis}

NSCLC 8 (61.5\%)

Head and neck SCC 2 (15.4\%)

Multiple myeloma 1 (7.7\%)

Breast cancer 1 (7.7\%)

Rectal cancer 1 (7.7\%)

\section{Tumor stage}

Stage IV 4 (30.8\%)

Stage III 7 (53.8\%)

Stage II 1 (7.7\%)

Unknown 1 (7.7\%)

\section{Ongoing treatment}

Radical or adjuvant/neoadjuvant radiotherapy 6 (46.2\%)

Palliative radiotherapy 4 (30.8\%)

Chemotherapy 4 (30.8\%)

Immunotherapy 2 (15.4\%)

\section{Treatment suspension}

No $6(46.2 \%)$
Table 3 Main COVID-19 positive patients' characteristics (Continued)

Temporary 1 (7.7\%)
Definitive 6 (46.2\%)
Chest radiograph
Positive 11 (84.6\%)
Negative 2 (15.4\%)
Chest CT scan
Positive 6 (46.2\%)
Negative 0
Not performed 7 (46.2\%)
CoviD-19 treatment
Hydroxychloroquine 11 (84.6\%)
Lopinavir/ritonavir 8 (61.5\%)
Other antivirals $3(23.1 \%)$
Tocilizumab 3 (23.1\%)
Azitromicin 9 (69.2\%)
No treatment 2 (15.4\%)
Respiratory support
Supplemental oxygen 10 (76.9\%)
Non-invasive ventilation 1 (7.7\%)
Invasive ventilation 0
CoviD-19 outcome
Negativized 6 (46.2\%)
Deceased 5 (38.5\%)

ECOG Eastern Cooperative Oncology Group, NSCLC Non Small Cell Lung Cancer, SCC Squamous Cell Carcinoma

the cases were receiving active treatment, mainly consisting of chemotherapy and immunotherapy or target therapy, and infection determined in almost all the cases treatment suspension [10-20].

In the first reports patients with ongoing radiotherapy were represented only by a total of three cases not described in detail $[10,11]$ and a 64 years old woman that, due to SARS-Cov-2 infection, suspended stereotactic radiotherapy for cT1bN0M0 NSCLC after 3 fractions (planned $55 \mathrm{~Gy} / 5$ in 5 fractions) [16].

Seven confirmed COVID-19 cases were identified in a prospective cohort at MD Anderson Radiation Oncology among 121 patients tested with RT-PCR [20]: six required hospitalization (four necessitating intensive care) and two (29\%) died; three were undergoing RT at the time of COVID-19 diagnosis, of whom one deceased, and two needed treatment suspension (one temporary and one definitive). Of note, treatment was deferred or interrupted in 40 subjects while awaiting RT-PCR results. 
The high rate of severe events described for patients on active treatment (reaching 83\%) might raise concern and deter physicians to carry on anticancer therapy during COVID-19 pandemic, with the risk to impair its effectiveness. Nevertheless, it is at least premature to draw conclusions derived from such circumscribed data: increased COVID-19 severity in subjects under active treatment was reported only in two cohorts of respectively 4 and 6 patients $[9,10]$.

Contrasting conclusions were obtained in a recent prospective observational study performed in the United Kingdom amidst 800 patients with a diagnosis of cancer and symptomatic COVID-19: global mortality was $28 \%$ and significantly higher risk was observed for males, with advancing age and in presence of comorbidities such as hypertension and cardiovascular diseases [21]. Active treatments, including systemic therapy and radiotherapy, within 4 weeks before SARS-Cov-2 positive RT-PCR had no significant effect on mortality from COVID-19. Mortality rate was $23.7 \%$ among the 76 patients that recently received $\mathrm{RT}$, but no detailed characteristics of radiation treatment, timing and possible delays or suspensions were reported.

We analyzed the data from 402 cancer patients that underwent anti-cancer treatments at our Department from February 24 to April 24,2020. Infection rate in this population was $3.23 \%$ and mortality rate $1.24 \%$. Although these numbers are higher than those calculated for the general population of Brescia province in the same period (respectively 1.01 and $0.19 \%$ ) (https://www.giornaledibrescia.it/brescia-e-hinterland/inumeri-della-pandemia-di-covid-19-nel-bresciano-1.34 76480), the high proportion of risk factors for severe disease (age, comorbidities, male sex and smoking habit) [22-24] among our population must be considered. Additionally, the number of infections and deaths in the general population of our district could have been possibly gone under-detected as only a small fraction of it underwent RT-PCR assays and a large excess in overall mortality has been observed compared to previous years (http://www.deplazio.net/ images/stories/SISMG/SISMG_COVID19.pdf). Among the 13 subjects with COVID-19 diagnosis confirmed by RT-PCR, mortality was $38.5 \%$, higher than previously reported (range $0-36 \%$ in previous studies) [1021]. This could be explained by unfavorable characteristics such as higher median age (range $56-68$ years in previous studies [10-20], with similar mortality in the only report with higher median age [13]), high percentage of stage III-IV disease, predominance of male sex, smoking habit and significant comorbidities. Moreover, two of the deceased were already in critical conditions before being infected by COVID-19. The most common cancer type in our cohort was NSCLC, as in almost all previous reports (range 25-58.3\%) with the highest reported proportion of $61.5 \%$. Chest CT-scan confirmed its high sensitivity, as suggestive findings were reported in all the examinations performed. Differently from previous reports, chest radiograph assessed with a dedicated score [25, 26] resulted positive in $84.6 \%$ of the cases. All the COVID-19 patients were treated in a hospital setting, the large majority received hydroxychloroquine (84.6\%), antiviral drugs (84.6\%), azythromicin (69.2\%) and supplemetal oxygen (84.6\%). The lack of available facilities during the epidemic peak precluded the chance to provide invasive ventilation to our patients. Symptoms resolved in all the survived patients, six obtained RT-PCR assay clearance and two were still positive and were transferred to other institutions in good general conditions. Although practicing in one of the regions with the highest concentration of confirmed cases and deaths worldwide, COVID-19 outbreak lead to the definitive or prolonged suspension of only $2.5 \%$ of the treatments ongoing during the index period, due to confirmed or highly suspect cases. This percentage drops to $1.5 \%$ considering only diagnosis confirmed by RT-PCR. Treatments were safely continued also in $46.2 \%$ of positive patients and $50 \%$ of patients with suggestive symptoms but negative RT-PCR. The global reduction of workload was limited: maximum decrease of radiotherapy sessions reached $17 \%$ and this reduction was limited to $11 \%$ at the end of index period. The administration of systemic treatments did not suffer a significant decrease and the number of follow up evaluations remained overall stable through an almost complete switch towards telemedicine modalities. By contrast, the procrastination of deferrable indications led to a conspicuous reduction of new treatment planning procedures throughout the whole month of March.

The experience of 17 Spanish centers reported in a recent paper [27] support the feasibility of continuing RT during COVID-19 pandemic. Fourteen of 1208 patients on active treatment developed COVID-19 confirmed by RT-PCR. The implementation of a multidisciplinary team and dedicated protocols allowed the completion of RT for 11 patients (78\%); only one patient died due to complications of the infections. Unfortunately, no detailed characteristics of patients, disease and treatment were reported. Considering the staff, $8 \%$ of the members developed COVID-19 and had to quarantine.

The outbreak involved also our staff, with a combined infection rate of $13.7 \%$, particularly elevated amid ward nurses (33.3\%); in almost all the cases, symptoms were mild. The relative shortage of personnel did not affect our Department's activity but entailed a temporary reallocation of five nurses. Remarkably 12 of the 13 first 


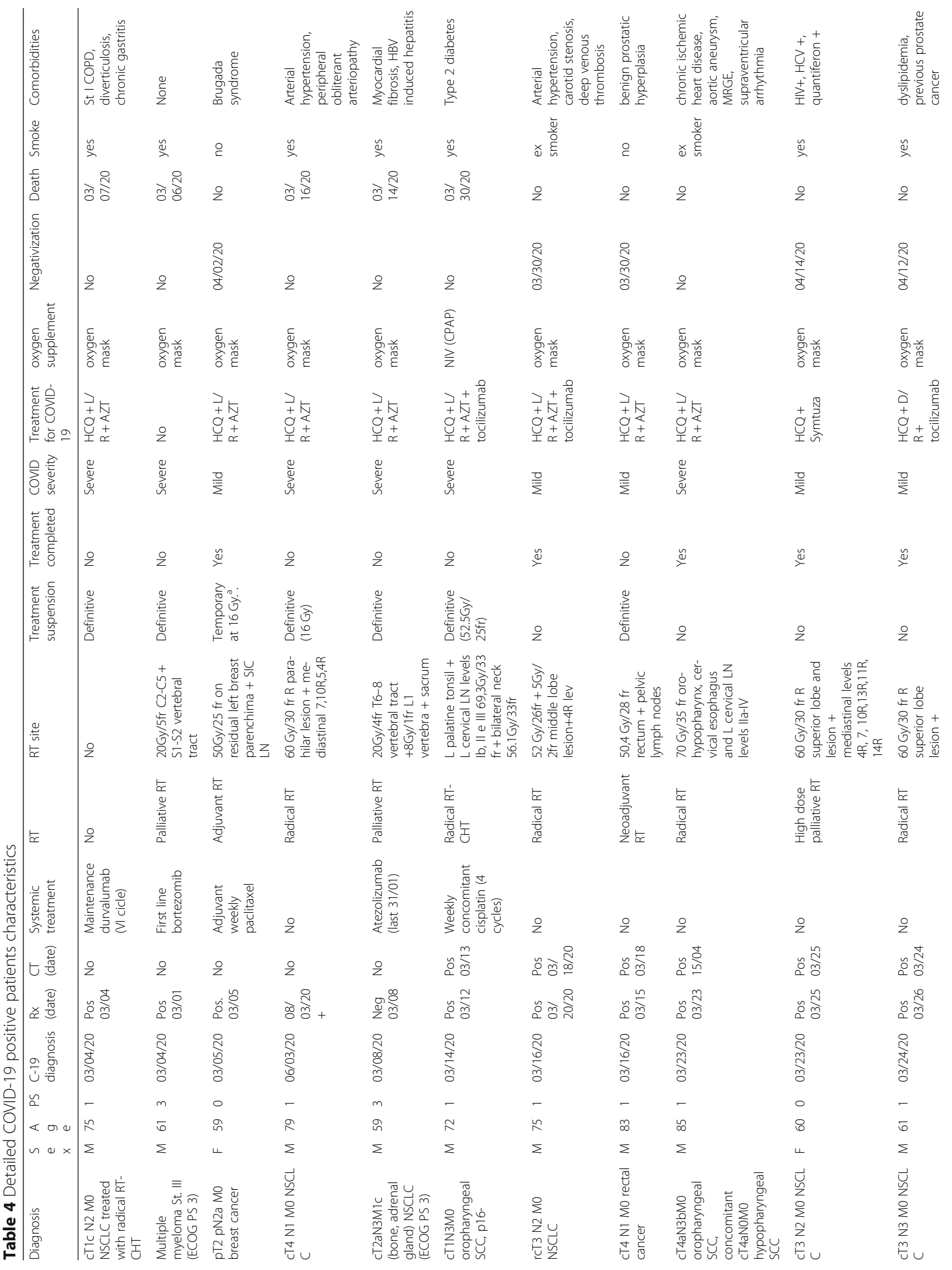




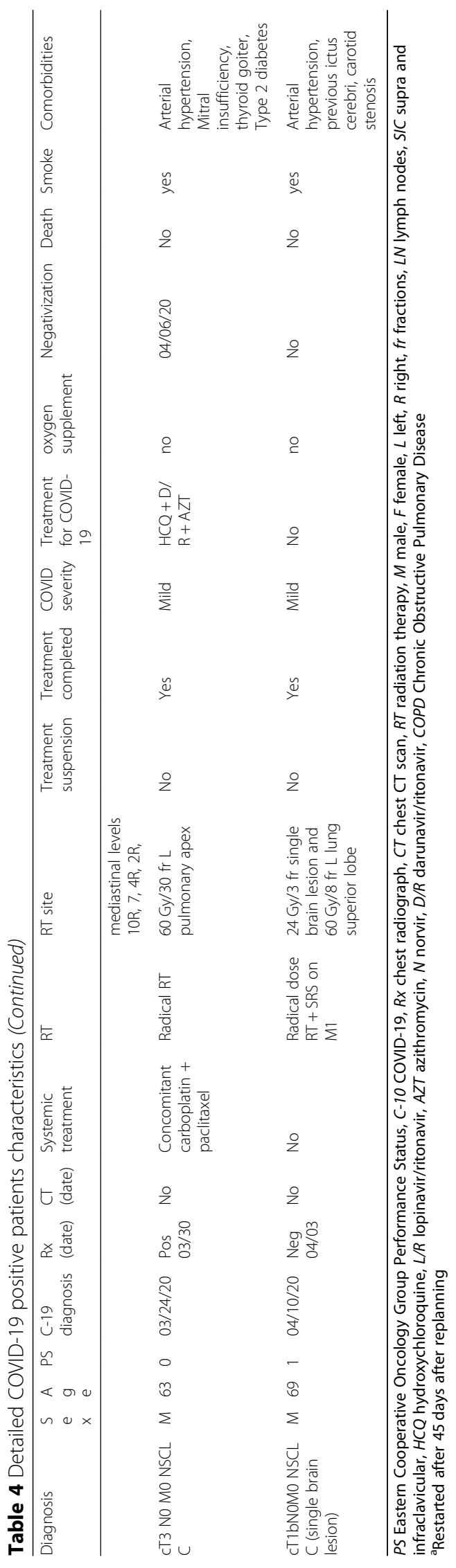


positive tests from patients were collected before March 24, 4 of the 5 deaths occurred within March 16 and all the positive cases among our staff were identified before March 17. In the first phases, the extent of the outbreak in Italy was underestimated and according the availability of PPE and preventive measures was sub-optimal. This, combined with the considerable rate of transmission from asymptomatic subjects [28] and the incubation time [29], could justify the high incidence of infection in the initial 2 weeks. The strict application of a dedicated workflow and the constant adoption of adequate PPE $[30,31]$ allowed us not only to contain and almost neutralize the diffusion of the infection, but also to carry on radiation therapy in patients positive for SARS-Cov-2 with mild or asymptomatic disease. The infection rate among patients undergoing treatment at our department outstandingly precipitated to $0.43 \%$ considering the period from March 25 to April 24 and no new contagion among our staff was observed in this time span. Our results corroborate the feasibility and safety of continuing anti-cancer treatment by endorsing consistent preventive measures, mitigating some concerns previously expressed [32,33]. We suggest to consider the risk of severe infection on a case-by-case basis and balance it with the effects generated by treatment delay or interruption. More than half of COVID-19 patients from our cohort had Stage III diseases amenable of curative treatment, which effectiveness could be heavily impaired by delay. Hypofractionation should be considered when feasible on a case by case basis [34-36], both to reduce the number of accesses and therefore limit the risk of infection for negative subjects and to complete ongoing treatment for COVID-19 positive asymptomatic or mildly symptomatic patients (as reported for two patients in our cohorts.

The limits of our study must be acknowledged. Although, to the best of our knowledge, this is the largest single-center series of COVID-19 patients ongoing radiation therapy, numbers are still small. A relatively high mortality rate was identified in this cohort, highlighting the need of a prompt diagnosis and an aggressive and timely treatment. As early detection of the infection is crucial, we advise to to screen all the patients with fever, suggestive symptoms or exposure to subjects with known or suspect infection with RT-PCR on nasopharyngeal swab before radiation therapy start [37, 38]. Differential diagnosis with pneumonitis induced by immunotherapy or ionizing radiation should also be considered for differential diagnosis [39]. Social distancing and the rigorous adoption of PPE proved to be pivotal to restrain viral spread and should be uphold until complete resolution of the outbreak. As for our experience, the absolute number of COVID-19 positive patients requiring compelling treatment for each
Institution is relatively low. The management of COVID-19 positive subjects could be therefore optimized with the implementation of dedicated pathways [40], preferentially defining a few specialized regional hub centers, where such patients could be centralized [41]. Fear of contagion should not divert from the urge to treat our patients, above all when a curative option is considered and if a delay could undermine its effectiveness. In this setting, the dread of a possible threat should not doom to a certain debacle.

\section{Abbreviations}

COVID-19: Coronavirus disease 19; RT-PCR: Real-time polymerase chainreaction; ECOG-PS: Eastern Cooperative Oncology Group Performance Status; NSCLC: Non-Small Cell Lung Cancer

\section{Acknowledgements}

We would like to thank the whole Radiation Oncology Department staff of the University - Spedali Civili Hospital, Brescia for their most generous and selfless commitment during this pandemic and for having contributed to the data collection:

Collaborating authors names: Manuela Adami, Alessandro Alghisi, Sara Barucco, Davide Bazzana, Elena Bedussi, Maria Luisa Biondi, Marco Lorenzo Bonù, Paolo Borghetti, Cristina Bresciani, Tazio Brontesi, Bruno Caraffini, Adriano Cavallini, Patrizia Cisca, Daniela Ciulli, Mariella Consoli, Lara Contrini, Marica Contessa, Flaviano Corrado, Loredana Costa, Antonietta Cristiano, Ana Croitoriu, Antonio De Agostini, Ivana De Vita, Francesca Di Gangi, Amelia Di Paolo, Giuseppina Di Virgilio, Alessandra Donofrio, Michele D'Oronzo, Michela Errico, Maria Grazia Facca, Giorgio Facheris, Adele Ferrari, Rosalia Fiorenza, Alfredo Fiume, Stefania Floriani, Antonella Franzoni, Giada Franco, Francesco Frassine, Sara Frassine, Giulia Gandinelli, Francesca Gandini, Stefania Garau,Manuela Ghidini, Barbara Ghedi, Gabriella Giammarresi, Amelia Giorgi, Roberta Gitti, Annamaria Guaineri, Giuseppe lannello, Jessica Imbrescia, Angela Inturri, Cinzia Inselvini, Sabrina Leali, Salvatore La Mattina, Salvatore La Mattina, Marta Maddalo, Emanuela Marini, Laura Maruca, Paola Mensi, Edoardo Pastorello, Sara Pedretti, Gloria Peretto, Biagio Piazza, Alessia Polonini, Giampietro Prandelli, Anna Premi, Claudio Provezza, Vanessa Ragazzoli, Elena Ranghetti, Alessandra Rinaldi, Carlo Alberto Rodella, Luca Romano, Elisabetta Rubini, Federica Saiani, Emiliano Salah, Valeria Santoro, Rossella Scala, Monica Scalvi, Mara Sessini, Navdeep Singh, Alessandra Taddeo, Fabrizia Terraneo, Cristian Toraci, Ottavia Turla, Paola Vitali, Giulia Volpi, Laura Zampedri.

\section{Authors' contributions}

$M B, A E G, S M M, F A, D T, N P$ and $L T$ contributed substantially to the conception of the article; $A E G, M B, M L, N B, A B, D T, D G, F B$ and $L T$ contributed substantially to collection of clinical informations and data; $M B, A E G, N P, L S, F A, L T, D T, D G$, $L M, G C$ and SMM contributed substantially to review of current literature; AEG, $N P, F A, M B, L T, D G, D T$ and SMM contributed substantially to writing of the manuscript and data interpretation; MB, AEG, NP, DT, LT, FA, FB, LM and SMM contributed substantially to drafting and revisiting. All authors have approved the manuscript and agree with its submission to "Radiation Oncology".

\section{Funding}

None to declare.

\section{Availability of data and materials}

Data are stored according to our Institutional protocols and are available upon request.

\section{Ethics approval and consent to participate}

The study was performed according to ASST Spedali Civili di Brescia Ethic Commitee principles. The study was conducted in agreement with the Declaration of Helsinki. All the patients signed a consent to share their clinical data and information for clinical studies. 


\section{Consent for publication}

All the patients signed a consent to share their clinical data and information for publication.

\section{Competing interests}

None to declare.

\section{Author details}

'Department of Radiation Oncology, Brescia University, Università degli Studi di Brescia, Piazzale Spedali Civili 1, 25123 Brescia, Italy. ${ }^{2}$ ASST Spedali Civili di Brescia, Department of Radiation Oncology, ASST Spedali Civili of Brescia, P.le Spedali Civili 1, 25123 Brescia, Italy.

Received: 10 June 2020 Accepted: 4 August 2020

Published online: 10 August 2020

\section{References}

1. https://www.cdc.gov/nchs/nvss/vsrr/COVID19/ Accessed June 06, 2020.

2. Buglione M, Cavagnini R, Di Rosario F, Maddalo M, Vassalli L, Magrini SM, et al. Oral toxicity management in head and neck cancer patients treated with chemotherapy and radiation: Xerostomia and trismus (part 2). Literature review and consensus statement. Crit Rev Oncol Hematol. 2016; 102:47-54. https://doi.org/10.1016/j.critrevonc.2016.03.012.

3. Buglione M, Jereczek-Fossa BA, Bonù ML, Franceschini D, Fodor A, Antognoni $P$, et al. Radiosurgery and fractionated stereotactic radiotherapy in oligometastatic/oligoprogressive non-small cell lung cancer patients: results of a multi-institutional series of 198 patients treated with "curative" intent. Lung Cancer. 2020;141:1-8. https://doi.org/10.1016/j.lungcan.2019.12.019.

4. Curigliano G. How to guarantee the best of care to patients with Cancer during the COVID-19 epidemic: the Italian experience. Oncologist. 2020. https://doi.org/10.1634/theoncologist.2020-0267.

5. Filippi AR, Russi E, Magrini SM, Corvò R. Letter from Italy: First practical indications for radiation therapy departments during COVID-19 outbreak. Int J Radiat Oncol Biol Phys. 2020. pii: S0360-3016(20)30930-30935. doi: https:// doi.org/10.1016/j.jijrobp.2020.03.007.

6. Meattini I, Franco P, Belgioia L, Boldrini L, Botticella A, Livi L et al. Radiation therapy during the coronavirus disease 2019 (covid-19) pandemic in Italy: a view of the nation's young oncologists. ESMO Open. 2020;5(2). pii: e000779. doi: https://doi.org/10.1136/esmoopen-2020-000779.

7. Guckenberger M, Belka C, Bezjak A, Bradley J, Daly ME, Palma D et al. Practice recommendations for lung cancer radiotherapy during the COVID19 pandemic: An ESTRO-ASTRO consensus statement. Radiother Oncol. 2020. pii: S0167-8140(20)30182-30181. doi: https://doi.org/10.1016/j.radonc. 2020.04.001.

8. Simcock R, Thomas TV, Estes C, Filippi AR, Katz MA, Saeed H, et al. COVID-19: Global radiation oncology's targeted response for pandemic preparedness. Clin Transl Radiat Oncol. 2020;22:55-68. https://doi.org/10.1016/j.ctro.2020. 03.009.

9. Liang W, Guan W, Chen R, Wang W, Li J, He J, et al. Cancer patients in SARS-CoV-2 infection: a nationwide analysis in China. Lancet Oncol. 2020; 21(3):335-7. https://doi.org/10.1016/S1470-2045(20)30096-6.

10. Yu J, Ouyang W, Chua MLK, Xie C. SARS-CoV-2 transmission in patients with Cancer at a tertiary Care Hospital in Wuhan, China. JAMA Oncol. 2020. https://doi.org/10.1001/jamaoncol.2020.0980.

11. Zhang L, Zhu F, Xie L, Wang C, Wang J, Zhou M et al. Clinical characteristics of COVID-19-infected cancer patients: a retrospective case study in three hospitals within Wuhan, China. Ann Oncol. 2020. pii: S0923-7534(20)3638336383. doi: https://doi.org/10.1016/j.annonc.2020.03.296.

12. Ma J, Yin J, Qian Y, Wu Y. Clinical characteristics and prognosis in cancer patients with COVID-19: A single center's retrospective study. J Inf Secur. 2020. pii: S0163-4453(20)30214-30210. doi: https://doi.org/10.1016/j.jinf. 2020.04 .006 .

13. Stroppa EM, Toscani I, Citterio C, Anselmi E, Zaffignani E, Codeluppi M, Cavanna L. Coronavirus disease-2019 in cancer patients. A report of the first 25 cancer patients in a western country (Italy). Future Oncol. 2020;14. https://doi.org/10.2217/fon-2020-0369.

14. Kalinsky K, Accordino MK, Hosi K, Hawley JE, Trivedi MS, Crew KD, Hershman DL. Characteristics and outcomes of patients with breast cancer diagnosed with SARS-Cov.2 infection at an academic center in New York City. Breast Cancer Res Treat. 2020:1-4. https://doi.org/10.1007/s10549-020-05667-6.
15. Luo J, Rizvi H, Egger JV, Preeshagul IR, Wolchok JD, Hellmann MD. Impact of PD-1 blockade on severity of COVID-19 in patients with lung cancers. Cancer Discov. 2020. pii: CD-20-C0596. doi: https://doi.org/10.1158/21598290.CD-20-0596.

16. Samson P, Ning MS, Shaverdian N, Shepherd AF, Gomez DR, Lin SH, et al. Clinical and radiographic presentations of COVID-19 among patients receiving radiation therapy for thoracic malignancies. Adv Radiat Oncol. 2020;11. https://doi.org/10.1016/j.adro.2020.04.020.

17. Trapani D, Marra A, Curigliano G. The experience on COVID-19 and cancer from an oncology hub institution in Milan, Lombardy Region. Eur J Cancer. 2020. https://doi.org/10.1016/j.ejca.2020.04.017.

18. de Marinis F, Attili I, Morganti S, Stati V, Spitaleri G, Passaro A, et al. Results of multilevel containment measures to better protect lung Cancer patients from COVID-19: the IEO model. Front Oncol. 2020;10:665. https://doi.org/10. 3389/fonc.2020.00665

19. Tagliamento M, Lambertini M, Genova C, et al. Call for ensuring cancer care continuity during COVID-19 pandemic. ESMO Open. 2020;5:e000783. https:// doi.org/10.1136/esmoopen-2020-000783.

20. Ning MS, McAleer MF, Jeter MD, Minsky BD, Ghafar RA, Das $P$, et al. Mitigating the Impact of COVID-19 on Oncology: Clinical and Operational Lessons from a Prospective Radiation Oncology Cohort Tested for COVID19. Radiother Oncol. 2020;S0167-8140(20):30293-0. https://doi.org/10.1016/j. radonc.2020.05.037

21. LYW L, Cazier JB, Starkey T, Turnbull CD, UK Coronavirus Cancer Monitoring Project Team, Kerr R, Middleton G. COVID-19 Mortality in Patients With Cancer on Chemotherapy or Other Anticancer Treatments: A Prospective Cohort Study. Lancet. 2020;S0140-6736(20):31173-9. https://doi.org/10.1016/ S0140-6736(20)31173-9.

22. Du RH, Liang LR, Yang CQ, Wang W, Cao TZ, Shi HZ et al. Predictors of Mortality for Patients with COVID-19 Pneumonia Caused by SARS-CoV-2: A Prospective Cohort Study. Eur Respir J. 2020. pii: 2000524. doi: https://doi. org/10.1183/13993003.00524-2020.

23. Li X, Xu S, Yu M, Wang K, Tao Y, Zhao J. Risk factors for severity and mortality in adult COVID-19 inpatients in Wuhan. J Allergy Clin Immunol. 2020. pii: S0091-6749(20)30495-30494. doi: https://doi.org/10.1016/j.jaci. 2020.04.006.

24. Miyashita H, Mikami T, Chopra N, Yamada T, Chernyavsky S, Rizk D, Cruz C. Do Patients with Cancer Have a Poorer Prognosis of COVID-19? An Experience in New York City. Ann Oncol. 2020. pii: S0923-7534(20)3930339300. doi: https://doi.org/10.1016/j.annonc.2020.04.006.

25. Borghesi A, Zigliani A, Masciullo R, Golemi S, Maculotti P, Farina D, Maroldi R. Radiographic severity index in COVID-19 pneumonia: relationship to age and sex in 783 Italian patients. Radiol Med. 202;125(5):461-4. https://doi.org/ 10.1007/s11547-020-01202-1.

26. Borghesi A, Maroldi R. COVID-19 outbreak in Italy: Experimental chest x-ray scoring system for quantifying and monitoring disease progression. Radiol Med. 2020;125(5):509-513. https://doi.org/10.1007/s11547-020-01200-3.

27. Suárez V, Moreno-Olmedo E, Pérez M, González EJ, Rivas D, Lopez E, et al. Spanish risk management framework across 17 radiation oncology centers during COVID-19 pandemic. Radiother Oncol. 2020;S0167-8140(20):30297-8. https://doi.org/10.1016/j.radonc.2020.05.041.

28. He D, Zhao S, Lin Q, Zhuang Z, Cao P, Wang MH, Yang L. The relative transmissibility of asymptomatic cases among close contacts. Int J Infect Dis. 2020. https://doi.org/10.1016/j.ijid.2020.04.034.

29. Lauer SA, Grantz KH, Bi Q, Jones FK, Zheng Q, Lessler J, et al. The incubation period of coronavirus disease 2019 (COVID-19) from publicly reported confirmed cases: estimation and application. Ann Intern Med. 2020. https:// doi.org/10.7326/M20-0504

30. Wei W, Zheng D, Lei Y, Wu S, Verma V, Han G, et al. Radiotherapy workflow and protection procedures during the coronavirus disease 2019 (COVID-19) outbreak: experience of the Hubei Cancer Hospital in Wuhan, China. Radiother Oncol. 2020;148:203-10. https://doi.org/10.1016/j.radonc.2020.03.029.

31. Tey J, Ho S, Choo BA, Ho F, Yap SP, Wang MLC, et al. Navigating the challenges of the COVID-19 outbreak: perspectives from the radiation oncology service in Singapore. Radiother Oncol. 2020;148:189-93. https:// doi.org/10.1016/j.radonc.2020.03.030.

32. Magrini SM, Borghetti P, Filippi AR, Scorsetti M, Jereczek-Fossa BA, Buglione $\mathrm{M}$ et al. Letter to the Editor Regarding ESTRO-ASTRO Guidelines on Lung Cancer Radiotherapy During COVID-19 Pandemic. Radiother Oncol. 2020. pii: S0167-8140(20)30215-30212. doi: https://doi. org/10.1016/j.radonc.2020.04.034. 
33. Jereczek-Fossa BA, Pepa M, Marvaso G, Bruni A, Buglione M, Donato V, et al. COVID-19 outbreak and Cancer radiotherapy disruption in Italy: survey endorsed by the Italian Association of Radiotherapy and Clinical Oncology (AIRO). Radiother Oncol. 2020;149:89-93. https://doi.org/10.1016/j.radonc. 2020.04.061.

34. Zhen H, Zhang F, Guan $\mathrm{H}$, et al. COVID-19 outbreak and cancer patient management: viewpoint from radio-oncologists. Radiother Oncol. 2020. https://doi.org/10.1016/j.radonc.2020.04.011.

35. Barra S, Guarnieri A, di Monale E Bastia MB, Marcenaro M, Tornari E, Corvò R et al. Short fractionation radiotherapy for early prostate cancer in the time of COVID-19: long-term excellent outcomes from a multicenter Italian trial suggest a larger adoption in clinical practice. Radiol Med 2020 15:1-5. doi: https://doi.org/10.1007/s11547-020-01216-9.

36. Portaluri M, Barba MC, Musio D, Tramacere F, Pati F, Bambace S. Hypofractionation in COVID-19 Radiotherapy: A Mix of Evidence Based Medicine and of Opportunities. Radiother Oncol. 2020;50167-8140(20): 30361-3. https://doi.org/10.1016/.radonc.2020.06.036.

37. Passaro A, Peters S, Mok TSK, Attili I, Mitsudomi T, de Marinis F. Testing for COVID-19 in lung cancer patients. Ann Oncol. 2020. pii: S09237534(20)39293-39290. doi: https://doi.org/10.1016/j.annonc.2020.04.002.

38. Xin Lian X, Shen J, Sun Y, et al. Under the coronavirus disease 2019 (COVID19) pandemic circumstance, how to administrate cancer patients with fever during radiotherapy. Radiother Oncol. 2020;150:15-7. https://doi.org/10. 1016/j.radonc.2020.05.049.

39. Guerini AE, Borghetti P, Filippi AR, Bonù ML, Tomasini D, Magrini SM et al. Differential diagnosis and clinical management of a case of COVID-19 in a stage III lung cancer patient treated with radio-chemotherapy and durvalumab. Clin Lung Cancer DOl: https://doi.org/https://doi.org/10.1016/j. cllc.2020.05.027.

40. Montesi, G., Di Biase, S., Chierchini, S. et al. Radiotherapy during COVID-19 pandemic. How to create a No fly zone: a Northern Italy experience Radiol Med 125, 600-603 (2020). https://doi.org/https://doi.org/10.1007/s11547020-01217-8.

41. National University Cancer Institute of Singapore (NCIS) Workflow Team. A segregated-team model to maintain cancer care during the COVID-19 outbreak at an academic center in Singapore. Ann Oncol. 2020. pii: S09237534(20)36410-36413. doi: https://doi.org/10.1016/j.annonc.2020.03.306.

\section{Publisher's Note}

Springer Nature remains neutral with regard to jurisdictional claims in published maps and institutional affiliations.

Ready to submit your research? Choose BMC and benefit from:

- fast, convenient online submission

- thorough peer review by experienced researchers in your field

- rapid publication on acceptance

- support for research data, including large and complex data types

- gold Open Access which fosters wider collaboration and increased citations

- maximum visibility for your research: over $100 \mathrm{M}$ website views per year

At $\mathrm{BMC}$, research is always in progress.

Learn more biomedcentral.com/submissions 